\title{
E्己̌ruAão \\ A Simetria nas Aulas de Matemática: uma proposta investigativa
}

\author{
Lidiane Schimitz Lopes' \\ Gilson Leandro Pacheco Alves' \\ André Luís Andrejew Ferreira' \\ 'Universidade Federal de Pelotas (UFPEL), Pelotas/RS - Brasil
}

RESUMO - A Simetria nas Aulas de Matemática: uma proposta investigativa. Este artigo apresenta um panorama acerca da didática da matemática e da simetria, além de uma proposta de atividades. Baseando-se em teorias que envolvem a didática da matemática, elaborou-se uma sequência didática fazendo uso de materiais acessíveis, possível de ser realizada em turmas numerosas. Paralelamente, pela Etnomatemática, percebe-se que ao longo da história, os padrões simétricos relacionam-se com o respectivo momento cultural. Nessa pesquisa, explora-se uma abordagem das transformações geométricas para o Ensino Fundamental. Por meio da aplicação e análise da sequência didática detalhada nesse trabalho, acredita-se ter contribuído para que surjam outras possibilidades, considerando sempre as especificidades de cada turma.

Palavras-chave: Didática da Matemática. Etnomatemática. Investigação. Simetria.

ABSTRACT - The Symmetry in Math Classes: an investigative proposal. This article presents an overview about the didactics of mathematics and symmetry, as well as an activity proposal. Based on theories involving didactics of mathematics, an instructional sequence using accessible materials, capable of being accomplished in numerous classrooms, was designed. At the same time, by means of ethnomathematics, it is noticed that, throughout history, symmetrical patterns are related to the respective cultural moment. In this search, an approach of geometric transformations for K-12 education is explored. Through this elaboration, application, and analysis of an instructional sequence, we believe that we have contributed for the emergence of other possibilities, always considering the specificities of each class.

Keywords: Didactics of Mathematics. Ethnomathematics. Investigation. Symmetry.

Educação \& Realidade, Porto Alegre, v. 40, n. 2, p. 549-572, abr./jun. 2015. 549 http://dx.doi.org/10.1590/2175-623646015 


\section{Introdução}

Grande parte do esforço matemático se concentra em modelar, ou seja, descobrir padrões para se descrever um fenômeno, seja ele natural, como os problemas da física, ou teórico, como o comportamento das séries numéricas, por exemplo. Seja qual for o enfoque ou contexto, investigar tem como consequência esperada descobrir. Segundo Ponte et al. (2003), investigar é um termo que pode ser entendido de várias maneiras. A investigação pode ser feita por profissionais especialistas de uma determinada área assim como por qualquer pessoa, em atividades do seu cotidiano. Nas aulas de matemática, a investigação pode se tornar uma aliada do professor para motivar o interesse dos estudantes.

Muito se especula sobre a eficácia das distintas formas de se ensinar matemática nas escolas. Com o objetivo de compreender, interpretar e descrever os fenômenos referentes ao ensino e à aprendizagem da matemática, a Educação Matemática configura-se com uma grande área de pesquisas educacionais, sejam no campo teórico ou prático. Quando se trata da articulação entre esses dois campos, surge como tendência a didática da matemática. Segundo Pais (2011, p. 11), “[...] todos os conceitos didáticos se destinam a favorecer a compreensão das múltiplas conexões entre a teoria e a prática e esta condição é um dos princípios dessa área de estudo”.

Algumas linhas de pesquisa, também chamadas de tendências da educação matemática, primam por dar significado ao aprendizado por meio da valorização do contexto do aprendiz e/ou das origens do conhecimento matemático que se pretende abordar. É caso das tendências conhecidas como História da Matemática e Etnomatemática. Todas essas linhas epistemológicas convergem para que o aluno produza significados para o conteúdo estudado em oposição à aprendizagem mecânica, como simplesmente decorar ou reproduzir algoritmos sem aplicação prática ou mesmo compreensão da teoria.

Nesse sentido a aprendizagem pela investigação configura-se como uma alternativa para auxiliar o estudante a dar sentido ao conteúdo ensinado, pois o conhecimento passa a ser consequência de uma postura ativa do aluno. Claro que uma atividade envolvendo investigação exige um preparo detalhado por parte do professor, com objetivos muito bem determinados. Entretanto, o docente deve esperar que surjam circunstâncias inusitadas, ou seja, perguntas e situações inéditas para as quais ainda não hajam repostas prontas.

Nesse artigo propõe-se e analisa-se uma atividade de investigação envolvendo conceitos de simetria previstos para o Ensino Fundamental. Aborda-se também a didática envolvida, aspectos conceituais da simetria que vão além da definição matemática, a descrição da atividade e análise de sua aplicação, realizada em outubro de 2013 em uma turma do $9^{\circ}$ ano do Ensino Fundamental. 


\title{
A Didática da Matemática: a transposição do saber científico para a sala de aula
}

Todos os dias letivos, em diferentes escolas e salas de aula, acontecem diversos momentos envolvendo professores, alunos e o conhecimento a ser ensinado. Há aqueles que não envolvem esses três elementos simultaneamente, como reuniões de professores e desses com seus alunos, grupos de estudo e pesquisas. Entretanto, situações que compreendem professores, alunos e saber com o objetivo de ensinar pertencem ao campo da didática.

Segundo Brousseau (2006), para Comenius, a didática, em seu aspecto amplo, pode ser dita como a arte de ensinar. Trata-se, portanto, das relações entre professor, aluno e saber. Segundo Pimenta (2013), essas relações podem ser explicitadas no triângulo:

\section{Figura 1 - Esquema das Relações entre Professor, Aluno e Conhecimento}

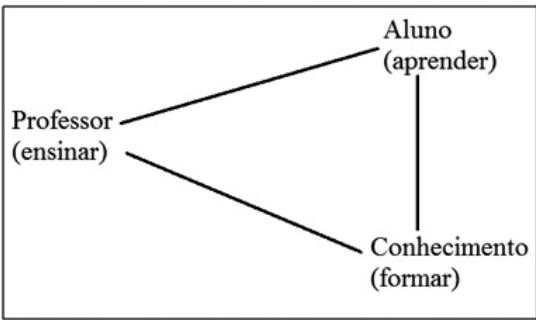

Fonte: elaboração dos autores, adaptado de Pimenta (2013).

De acordo com Pais (2011, p. 11), é possível definir a didática da matemática como

\begin{abstract}
[...] uma das tendências da grande área de educação matemática, cujo objeto de estudo é a elaboração de conceitos e teorias que sejam compatíveis com a especificidade educacional do saber escolar matemático, procurando manter fortes vínculos com a formação de conceitos matemáticos, tanto em nível experimental da prática pedagógica, como no território teórico da pesquisa acadêmica.
\end{abstract}

É inegável que são necessárias várias mudanças nos objetos matemáticos para adaptá-los do mundo da pesquisa para o ambiente escolar. A essas transformações chama-se transposição didática. Tal conceito pode ser entendido "[...] como um caso especial da transposição dos saberes, sendo esta entendida no sentido da evolução das ideias, no plano histórico da produção intelectual da humanidade" (Pais, 2011, p. 17). Segundo Silva (2008, p. 153), o conceito estabelecido por Chevallard para transposição didática afirma que “[...] não se ensina o saber científico, mas sim uma versão transposta dele, um saber adaptado para ser ensinado", constitui um conceito clássico de didática. 
A Simetria nas Aulas de Matemática

Enquanto o saber científico está associado às universidades, é registrado em uma linguagem codificada, é validado pelos paradigmas da área e o meio acadêmico busca desligá-lo do contexto, o saber escolar está condicionado pelas relações entre professor, aluno e saber, bem como representa o conjunto dos conteúdos das diferentes disciplinas escolares e envolve simulações de descobertas, valorizando e buscando o contexto, além de fugir de termos teóricos e formais. Segundo Pais (2011, p. 22), “[...] na passagem do saber científico ao saber previsto na educação escolar, ocorre a criação de vários recursos didáticos, cujo resultado prático ultrapassa os limites conceituais do saber matemático".

Outro ponto a ser destacado é a diferença entre conhecimento e saber. Se, por um lado, o saber está ligado ao plano histórico da produção de uma área disciplinar, o conhecimento, por sua vez, está submetido aos vínculos da dimensão pessoal do sujeito dedicado em entender um saber. Assim, o conhecimento é considerado mais próximo do fenômeno da cognição (Pais, 2011).

No processo da transposição didática, a aliada para a estruturação de uma educação matemática com significado é a contextualização. Segundo Pais (2011, p. 27), “[...] a contextualização do saber é uma das mais importantes noções pedagógicas [...]. Trata-se de um conceito didático fundamental para a expansão do significado da educação escolar". Ainda de acordo com o autor, há um acréscimo no valor educacional de uma disciplina no momento em que o estudante percebe e compreende as relações entre o conteúdo estudado e um contexto entendido por ele. Tendências como a História da Matemática e a Etnomatemática são opções para o docente (re)criar/apresentar um contexto para os objetos ensinados em suas aulas.

Nesse sentido, D’Ambrósio (2012, p. 29) destaca que “[...] do ponto de vista de motivação contextualizada, a matemática que se ensina hoje nas escolas é morta" e, como consequência disso, de acordo com Silva (2008), são diagnosticados altos índices de alunos do Ensino Médio e Fundamental que não conseguem adquirir os conhecimentos matemáticos apropriados para cada faixa etária. Assim, “[...] o desafio didático consiste em fazer essa contextualização, sem reduzir o significado das ideias matemáticas que deram origem ao saber ensinado" (Pais, 2011, p. 26).

Ainda sobre contextualização, o professor de matemática, ao contrário do cientista que busca desvincular-se do contexto com o objetivo de atingir níveis mais amplos de generalidade, deve recontextualizar o conteúdo ensinado, tentando relacioná-lo a situações que sejam mais compreensíveis aos alunos. Entretanto, Pais (2011) salienta que esse contexto reconstituído não é o mesmo daquele onde o saber foi inicialmente elaborado. "Enquanto para o pesquisador, o saber matemático é o seu principal objeto de estudo, na prática pedagógica, o saber escolar é um instrumento educacional para a promoção existencial do aluno" (Pais, 2011, p. 32-33). 
Sem dúvidas, é evidente que a reconstituição de contextos está diretamente ligada à concepção epistemológica que o professor tem da sua disciplina. Entende-se a epistemologia do docente como "[...] as concepções referentes à disciplina com que trabalha esse professor, oriundas do plano estrito de sua compreensão e que conduzem uma parte essencial de sua postura pedagógica” (Pais, 2011, p. 34). Muitas crenças, originadas em conhecimentos empíricos e perpetuadas pelo tempo, podem gerar uma visão puramente pessoal sobre a ciência ensinada. Nesse momento, nasce um conflito entre a visão subjetiva e a intenção de objetividade que deve caracterizar a aprendizagem escolar. Segundo Pais (2011, p. 34), “[...] mesmo que haja a intenção de uma permanente aproximação entre a compreensão do professor e a essência objetiva do conceito, é preciso estar atento às possíveis divergências entre esses dois níveis".

Um dos pontos que requer atenção especial do docente é o tempo de aprendizagem. Diferente em essência do tempo didático, que é estabelecido por programas e livros didáticos em cumprimento a uma exigência legal, o tempo de aprendizagem está vinculado com os rompimentos e conflitos do conhecimento, necessitando de uma reorganização de informações. $\mathrm{O}$ ato de aprender é justamente caracterizado por esses conflitos. Assim, pode-se afirmar que o tempo de aprendizagem é diferente para cada sujeito e não sequencial, pois cada um pode ter a necessidade de retomar concepções precedentes e reorganizá-las, transformando-as em um novo conhecimento.

Os momentos em que ocorrem as relações entre professor, alunos e saber com vistas à aprendizagem dentro de um planejamento preestabelecido são denominados situações didáticas. Em contrapartida, é consenso que muitas aprendizagens ocorrem fora desses momentos, também em ambientes externos à escola. Essas ocasiões são ditas como situações adidáticas.

\section{As Situações (a)didáticas}

Durante a vida escolar, o estudante vivencia diferentes momentos que possibilitam a ampliação de seus conhecimentos científicos. Pesquisas na internet ou em livros, sejam elas motivadas por interesses pessoais ou tarefas estabelecidas pelo professor, grupos de estudo e a própria aula constituem alguns desses momentos. Entretanto, nem todas as situações que envolvem conhecimentos científicos e alunos podem ser consideradas situações didáticas. Segundo Pais (2011, p. 65), “[...] uma situação didática é formada pelas múltiplas relações pedagógicas estabelecidas entre o professor, os alunos e o saber, com a finalidade de desenvolver atividades voltadas para o ensino e para a aprendizagem de um conteúdo específico".

O autor destaca ainda a relevância da presença dos três elementos - professor, aluno e saber - para caracterizar a sala de aula como 
A Simetria nas Aulas de Matemática

um espaço vivo, rico em situações didáticas. Na falta de um desses três elementos, há uma situação de estudo envolvendo alunos e saber ou, até mesmo, uma simples reunião entre estudantes e professor, sem a valorização de um conteúdo. Em contrapartida, a presença desses três componentes não é suficiente para abarcar toda a complexidade de uma situação didática, destacando a necessidade de recorrer a outros elementos do sistema didático, tais como métodos, posições teóricas, objetivos e recursos.

No âmbito da matemática, há especificidades na forma de apresentação dos conteúdos que influenciam a prática pedagógica do professor. A forma como esses conhecimentos estão estruturados em programas e livros didáticos, priorizando a matemática fechada em si mesma, exige que o professor ultrapasse esses limites para contextualizar o saber a ser ensinado. De acordo com Pais (2011), a ausência de um vínculo palpável com a realidade faz com que se perca a dimensão dos valores educativos do conteúdo apresentado.

Como um dos objetivos da Educação Matemática é proporcionar ou, no mínimo, contribuir para que os alunos desenvolvam autonomia intelectual que os possibilite compreender melhor o mundo onde vivem, deve-se considerar as situações que não estão sob o controle pedagógico do professor, mas contribuem para a formação de conceitos do saber escolarizado. Pais (2011) afirma que uma situação adidática é composta por fenômenos de aprendizagem que ocorrem além das intenções pedagógicas do docente, seja em sala de aula ou em ambientes externos. Nesse sentido, D’Amore (2007, p. 5) destaca que, na situação adidática, “[...] um sujeito é levado a 'fazer' matemática, a utiliza-la ou inventa-la, sem a influência de condições didáticas específicas determinadas e explicitadas pelo professor".

Em torno de uma situação didática podem existir diversas adidáticas. Isso ocorre quando o aluno consegue resolver problemas e utilizar, por ele mesmo, o conhecimento que está construindo em algumas situações não previstas e/ou na ausência do professor. "A potencialidade das situações adidáticas está, justamente, voltada para a tentativa de romper com velhas práticas de repetição e do modelo, que tanto influenciaram uma vertente da pedagogia tradicional" (Pais, 2011, p. 68).

Assim, mesmo que o professor estabeleça sua prática com a intencionalidade de criar uma situação didática para atingir determinados objetivos, os momentos de aprendizagem que estão fora de seu controle pedagógico também contribuem na construção do conhecimento científico dos estudantes.

\section{A Engenharia Didática e a Sequência Didática}

Ancorada nos pressupostos da Engenharia Didática, a sequência didática em matemática constitui-se como um método de trabalho baseado na organização esquemática e sequencial de etapas objetivando 
criar situações de aprendizagem. A Engenharia Didática, em essência, é considerada uma forma de organização dos procedimentos metodológicos da pesquisa em didática da matemática por contemplar tanto os aspectos teóricos quanto os experimentais.

De acordo com Artigue (1996), segundo Pais (2011, p. 100):

$$
\begin{aligned}
& \text { [...] a engenharia didática expressa uma forma de trabalho } \\
& \text { didático comparável com o trabalho do engenheiro na rea- } \\
& \text { lização de um projeto arquitetônico [...], envolvendo des- } \\
& \text { de os desafios da criatividade inicial, por ocasião da ges- } \\
& \text { tação de suas primeiras ideias, até sua execução prática. }
\end{aligned}
$$

Entretanto, cabe ressaltar que a comparação com a execução de um projeto não significa que será de uma forma automatizada, com repetições idênticas e sem considerar as diferentes variáveis iniciais ou as que surgem no decorrer do processo. Por se tratar do estabelecimento de uma correlação entre teoria e prática, os procedimentos organizados a partir da metodologia Engenharia Didática possibilitam ao pesquisador transitar entre suas diferentes fases ${ }^{1}$, conforme forem surgindo necessidades.

Nessa perspectiva, considera-se sequência didática como um conjunto de atividades ligadas entre si, planejadas para ensinar um conteúdo, etapa por etapa. Envolvendo práticas para a aprendizagem e avaliação, a organização de uma sequência didática está intimamente ligada aos objetivos que se deseja alcançar com os alunos.

Pais (2011) acrescenta que uma sequência didática constitui-se de diferentes momentos em aula, executados em um mesmo dia ou não, cujas atividades são planejadas e analisadas previamente com a intenção de observar situações de aprendizagem. "Tal como acontece na execução de todo projeto, é preciso estar atento ao maior número possível de informações que podem contribuir no desvelamento do fenômeno investigado" (Pais, 2011, p. 102).

No geral, sequências didáticas são compostas por sete etapas com diferentes durações, estabelecidas de acordo com o conteúdo que se quer abordar. São elas: definição do público alvo, dos conteúdos, da duração, dos objetivos geral e específicos, do material necessário para a execução, da descrição das situações de ensino e da avaliação.

A elaboração de sequências didáticas configura-se como um excelente ponto de partida para o planejamento de atividades interdisciplinares, pois permite a visão da ação pedagógica como um todo e, a partir disso, o desenvolvimento de situações didáticas para cada encontro.

\section{A Simetria Através dos Tempos: aspectos históricos e culturais}

Através dos tempos, percebe-se que as grandes construções que perpetuaram e transmitem a herança cultural dos povos apresentam 
padrões de simetria. Rooney (2012, p. 73) destaca que “[...] os primeiros contatos com a geometria são anteriores aos sistemas de números e escritos" e que os povos antigos deixaram inúmeras evidências de seus interesses por padrões repetidos e simetria de formas em objetos, decorações e estruturas. Alguns dos registros mais antigos datam do Período Neolítico, considerado último período da Idade da Pedra e cujo início se deu por volta de 8.000 a. C.. Segundo Boyer e Merzbach (2012, p. 26)

O homem neolítico pode ter tido pouco lazer e pouca necessidade de medir terras, porém seus desenhos e figuras sugerem uma preocupação com relações espaciais que abriu caminho para a geometria. Seus potes, tecidos e cestas mostram exemplos de congruência e simetria, que em essência são partes da geometria elementar e aparecem em todos os continentes.

\section{Figura 2 - Exemplo de Arte do Período Neolítico}

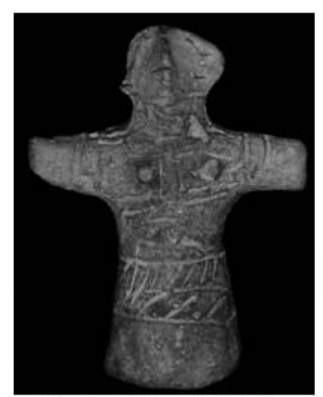

Fonte: Silva (2008)

Na civilização egípcia antiga é evidente o uso de um padrão em suas criações. Buscando criar figuras de fácil compreensão, os egípcios valiam-se do equilíbrio e da simetria para criar composições altamente organizadas. Segundo Enright (2013), os artistas desenhavam grades formadas por linhas verticais e horizontais para criar proporções exatamente iguais. Durante esse mesmo período, na Mesopotâmia, os sumérios desenvolveram igualmente o senso de proporções, porém suas composições não eram tão elaboradas quanto as egípcias.

\section{Figura 3 - Exemplo de Arte Egípcia}

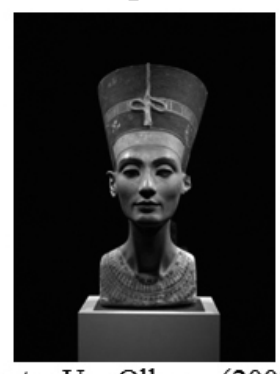

Fonte: Um Olhar... (2008). 
Figura 4 - Exemplo de Arte Suméria

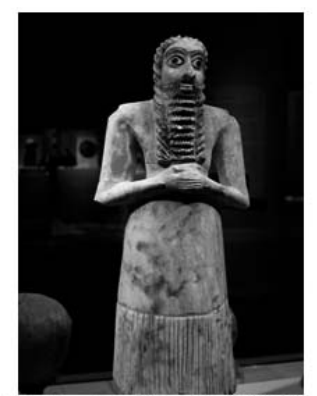

Fonte: ArteEspaña (2005).

A arte da Grécia Antiga, por volta do século V a. C., estabelece um sistema de proporções ideais, possibilitando a construção de grandes obras como, por exemplo, o Partenon. Na Roma Antiga, o arquiteto Marco Vitrúvio Polion desenvolveu a obra intitulada De architectura libri decem, contendo informações sobre a construção de cidades, considerando as necessidades de proteção e conforto da população.

Durante a Idade Média, as composições artísticas eram marcadas pela religiosidade tendo a simetria como base. Na arquitetura isso se tornou mais evidente e característico na construção de grandes igrejas.

\begin{abstract}
A estética da proportio era verdadeiramente a estética da Idade Média por excelência. O princípio de simetria, também nas suas expressões mais elementares, era um critério instintivo de tal modo radicado no espírito medieval que era susceptível de determinar a própria evolução do repertório iconográfico. Este provinha da Bíblia, da liturgia, [...] mas, frequentemente, exigências de simetria levavam a modificar uma cena que a tradição tinha transmitido em termos bem definidos, e até a violar os hábitos e a verdade histórica mais comum (Eco, 1989, p. 53).
\end{abstract}

Percebe-se que, muito além de um conceito matemático como é conhecido hoje, a simetria na Idade Média era requisito primordial para a beleza artística.

Nos séculos conhecidos como Renascimento, houve a valorização e retomada da arte da Antiguidade Clássica, além da valorização do homem e visão científica da natureza. O desenvolvimento nas artes plásticas, especialmente, buscava a beleza por meio de proporções e simetrias, de acordo com os parâmetros ditados pelo belo clássico.

Boyer e Merzbach (2012, p. 211) destacam que "[...] o Renascimento poderia perfeitamente ter desenvolvido a geometria pura na direção sugerida pela arte e pela perspectiva", entretanto, a criação da geometria algébrica modificou o interesse dos matemáticos da época.

Desde tempos remotos até a atualidade, a arte islâmica é baseada em traços simétricos, com padrões de repetição. As formas poligonais 
simétricas utilizadas para a criação desses padrões podem ser infinitamente estendidas, repercutindo conceitos da geometria moderna. Os árabes são os criadores dos mosaicos geométricos.

Evidencia-se aqui, através de alguns exemplos, que o conceito de simetria atravessa várias culturas de diferentes povos em épocas distintas. Hoje se entende simetria como um fundamento ou propriedade matemática, mas, ao analisar historicamente, constata-se que a percepção simétrica precede e/ou não necessita de formalismo matemático.

\section{A Cultura nas Formas e a Etnomatemática Envolvida}

Não é difícil perceber e relacionar o desenvolvimento cultural das civilizações com sua herança arquitetônica. Nos povos mais conhecidos da antiguidade (egípcios, gregos e romanos) a herança histórica material mais evidente são suas grandiosas edificações que atravessaram os milênios. As pirâmides no Egito, o Partenon na Grécia e o Coliseu em Roma são exemplos e símbolos da força cultural, econômica e militar vivida por esses povos.

Porém, a sustentação dessas civilizações como centro de poder no mundo, cada uma em seu tempo, muito se deu pela detenção do conhecimento científico, em especial o matemático. A matemática de cada civilização, local e temporalmente específica, colaborou para a resolução de seus problemas mais básicos, como alimentação e proteção, mas também se fez presente na manifestação cultural desses povos através da construção e do embelezamento de suas edificações.

Figura 5 - Partenon

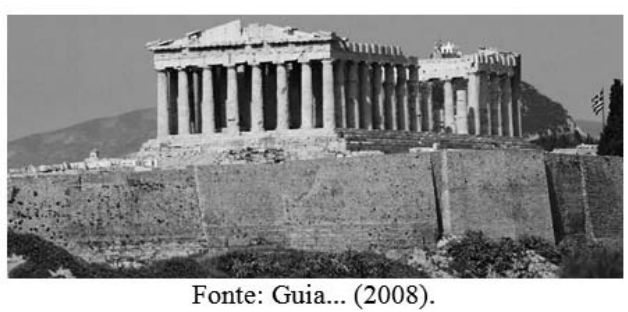

É impossível se referir à beleza arquitetônica sem falar em simetria. Por sua vez, não se pode explicar a simetria detendo-se apenas à assepsia das formas geométricas ideais como o triângulo, a circunferência ou os sólidos de Platão. Até mesmo porque a perfeição dessas formas pode ser considerada uma condição abstrata só concebível no nível do pensamento, enquanto a harmonia nas formas de um edifício é algo sensível.

No entanto, mesmo ideal ou abstrata, a geometria ou matemática das formas, é um dos pilares da engenharia e arquitetura de resultados tão concretos.

558 Educação \& Realidade, Porto Alegre, v. 40, n. 2, p. 549-572, abr./jun. 2015. 
Voltando à simetria, pode-se dizer que a identificamos em muitas coisas concretas à nossa volta. Na natureza, também a percebemos, mas não se pode ter certeza se as formas naturais se fizeram simétricas ou se simplesmente nossos olhos, viciados em matemática, reconhecem nelas tal característica. As asas de uma bela borboleta são simétricas ou atribuí-se simetria matemática a algo que é naturalmente belo?

Como em relação às formas naturais essa dúvida não será facilmente superada, convém focar nas construções humanas, tais como a própria matemática. Não são necessários profundos conhecimentos de engenharia e arquitetura para saber que desenho e construção estão intimamente ligados: normalmente na elaboração do projeto. E o desenho, sendo a representação das formas, nos remete à geometria. De forma simplificada se fecha o enlace entre arquitetura e matemática.

Figura 6 - Coliseu

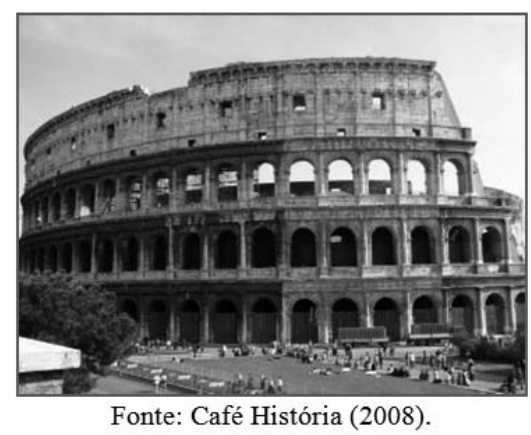

Voltando ao enfoque da arquitetura como uma manifestação cultural, é sabido que os pesquisadores dessa área não tem dificuldade, ao analisar uma edificação antiga, em dizer para que se prestava e qual período histórico fora construída e utilizada. Se as formas de um prédio, estrada, ponte, monumento ou de qualquer outra construção são capazes de revelar seu contexto, isso também revela que existe uma matemática específica, ou seja, uma Etnomatemática envolvida.

Estudos na linha da Etnomatemática destacam que houve uma geometria a serviço da engenharia, da arquitetura e das construções artísticas de diferentes civilizações e grupos sociais (D’Ambrósio, 2007). Seja essa matemática genuína da sociedade que a utilizou ou carregada de influências estrangeiras, foi o senso de proporções e simetrias que possibilitou tais construções.

Segundo Santos (2007), a verdadeira beleza é sempre a natural ou geométrica. Em seu trabalho intitulado A Matemática da Arquitetura Ideal, essa pesquisadora faz referência a Vitrúvio ${ }^{2}$, como sendo o primeiro a relacionar e tomar como padrão para o belo, referindo-se às formas, as proporções e simetria do corpo humano. Ressalta ainda que o conceito de simetria de Vitrúvio é diferente do qual é usualmente 
A Simetria nas Aulas de Matemática

adotado hoje em matemática. Para ele, simetria é a relação entre os vários elementos do plano e cada um desses elementos com os do corpo humano. Essa correlação ou comparação também pode ser entendida como proporção.

Dessa forma, entende-se que a matemática de um povo também se revela culturalmente através da arquitetura e da arte, se é que é possível separá-las. E por que não perguntar simplesmente pela matemática utilizada e sim pela Etnomatemática envolvida? D’Ambrósio (2007), ao defini-la como a matemática dos distintos grupos sociais, não descarta a matemática europeia, tão influente no ensino acadêmico, de ser apenas mais um tipo de Etnomatemática. Pela abordagem histórica que foi feita e pela opção de se evidenciar as culturas de distintos povos em diferentes épocas, considera-se conveniente a adoção do termo e da abordagem Etnomatemática.

\section{Investigando a Simetria em Sala de Aula}

Investigar é um termo que pode ser empregado de várias maneiras. Para algumas pessoas, trata-se de um trabalho realizado apenas por investigadores profissionais. Para outras, é uma atividade que pode ser desenvolvida no dia a dia das pessoas das mais diferentes esferas sociais. Em sala de aula, a investigação pode ser aliada na formação dos alunos e prática dos professores. "Para os matemáticos, investigar é descobrir relações entre objetos matemáticos conhecidos ou desconhecidos, procurando identificar as respectivas propriedades" (Ponte et al., 2003, p. 13).

Nos Parâmetros Curriculares Nacionais - PCN (1998) para o ensino de matemática, encontra-se como objetivos para a disciplina em sala de aula "identificar características de figuras geométricas, percebendo semelhanças e diferenças entre elas, por meio de composição e decomposição, simetrias, ampliações e reduções” (Brasil, 1998, p. 56), bem como a "[...] identificação de semelhanças e diferenças entre polígonos, usando critérios como número de lados, número de ângulos, eixos de simetria, etc." (Brasil, 1998, p. 60). O documento traz também a relevância de desenvolver atitudes como a sensibilidade para observar simetrias e outras formas geométricas em construções, nas artes, na natureza.

Apresenta-se, nesse trabalho, uma proposta para a introdução do conteúdo de Simetrias, aplicada em uma escola da rede particular de ensino na cidade de Bagé/RS.

\section{A Proposta e a Aplicação da Atividade}

A sequência didática organizada para a execução dessa proposta considerou como objetivo introduzir o conteúdo Simetria por meio de atividades direcionadas que relacionassem os conceitos ensinados com

560 Educação \& Realidade, Porto Alegre, v. 40, n. 2, p. 549-572, abr./jun. 2015. 
situações da vida dos estudantes. Organizada em quatro etapas, a sequência didática foi planejada para 4 horas/aula.

Nas três primeiras etapas dessa atividade, os alunos poderão estar dispostos em duplas ou trabalharem de forma individual. Para o desenvolvimento dessa proposta cada estudante (ou dupla) precisará dos seguintes materiais.

- 2 folhas de papel quadriculado;

- 1 folha de papel carbono;

- 2 folha de papel ofício;

- Lápis;

- Borracha;

- Régua.

Na quarta etapa, se os estudantes trabalharam de forma individual, passarão a trabalhar em duplas. Caso a disposição dos alunos inicial seja em duplas, eles serão organizados em quartetos para a execução da quarta etapa.

A atividade foi aplicada no mês de novembro de 2013 em uma escola da rede privada de ensino, no município de Bagé/RS, em uma turma de $9^{\circ}$ ano do Ensino Fundamental. A turma contava com 13 alunos, dos quais 2 eram repetentes. Por se tratar de um projeto em parceria com a escola, e de acordo com o planejamento da sequência didática, todas as etapas foram realizadas em uma manhã, ocupando 4 horas/ aula, tempo previsto no planejamento.

Durante a distribuição do material, os alunos mostraram-se curiosos, querendo entender como usariam aquilo em uma aula de matemática. Em todas as etapas da proposta os estudantes participaram ativamente, realizando as atividades com interesse.

\section{$1^{a}$ etapa - investigando a simetria por reflexão}

A proposta dessa etapa está no fato dos alunos criarem figuras simétricas espontaneamente, a partir de um desenho livre.

Uma folha de papel ofício deverá ser dobrada ao meio, marcando a linha que divide a folha. Os alunos deverão unir a folha de papel ainda aberta com o papel carbono de modo que o "lado que escreve" do carbono esteja em contato com a folha. Ao refazer a dobra, o carbono deve permanecer no seu interior, conforme a Figura 7 abaixo. 


\section{Figura 7 - Dobra do Papel e Carbono}

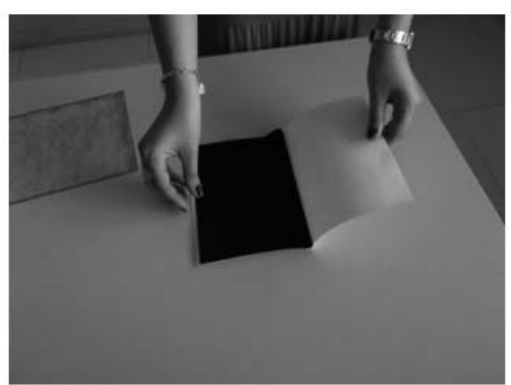

Fonte: elaboração dos autores.

Ao criarem uma figura qualquer em um dos lados do papel quadriculado (Figura 8), os alunos criarão duas figuras simétricas por reflexão na parte interna dessa folha (Figura 9). O professor pode estimular o raciocínio dos alunos com algumas questões como: "o que aconteceu na parte de dentro dessa folha?”; "as figuras criadas são parecidas ou são iguais?”; "há diferenças entre elas? Quais?”; "vemos isso acontecer na nossa vida?"; "quando estamos na frente do espelho, o que acontece?"; "se fizermos um desenho longe da dobra do papel, como ele fica na parte de dentro?"; "e se fizermos um bem próximo à linha da dobra, o que acontece?".

Figura 8

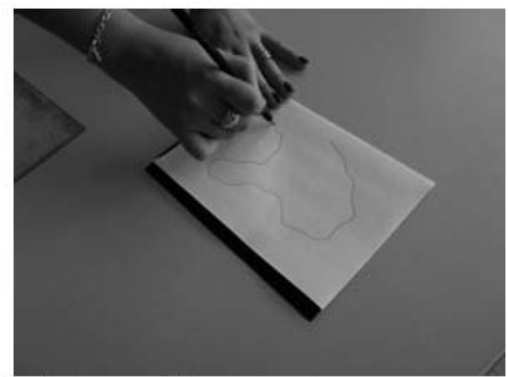

Fonte: elaboração dos autores.

Figura 9

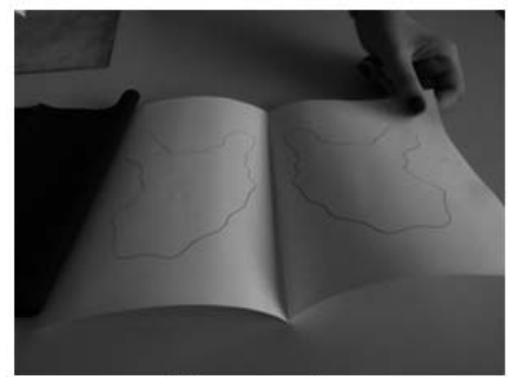

Fonte: elaboração dos autores. 
A partir da análise realizada nessa figura, os alunos, com a mediação do professor, perceberão que a linha do meio divide o desenho em dois lados iguais, ou seja, a marca da dobra do papel representa um eixo que divide o desenho em dois lados simétricos. Assim, naturalmente, os estudantes construirão o conceito de eixo de simetria.

\section{$1^{a}$ etapa - investigando a simetria por reflexão: análise da aplicação}

A primeira etapa foi executada com curiosidade, pois os estudantes não sabiam o que esperar, o que encontrariam ao abrir a folha dobrada ao meio. Muitos se empenharam em fazer desenhos bonitos e elaborados. Ao abrir a folha ficaram surpresos ao perceber o desenho criado com o carbono.

\section{Figura 10}

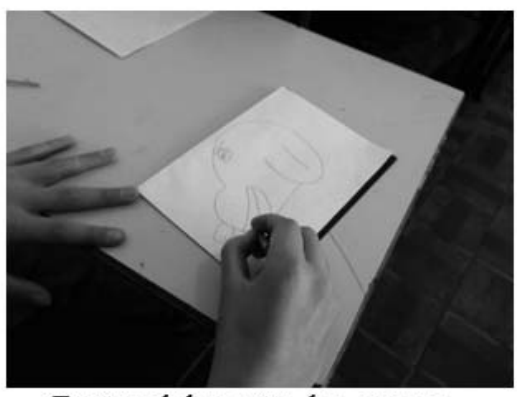

Fonte: elaboração dos autores.

Figura 11

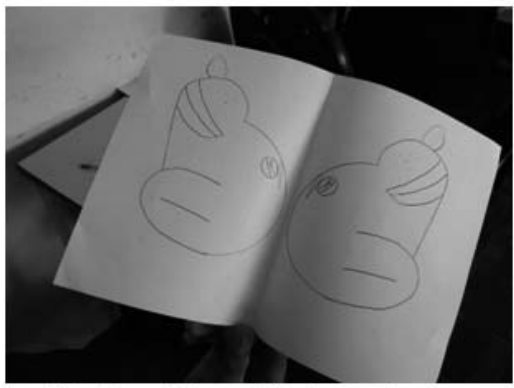

Fonte: elaboração dos autores.

Durante os questionamentos previstos na sequência didática, os estudantes afirmaram que as figuras criadas nos dois lados da folha eram iguais, mas estavam "viradas". Um deles questionou se as figuras poderiam ser consideradas diferentes só porque estavam viradas. Nesse momento, uma aluna afirmou: "O que aconteceu aqui é o que acontece no espelho: um reflexo!”.

Educação \& Realidade, Porto Alegre, v. 40, n. 2, p. 549-572, abr./jun. 2015. 
Quando perguntados sobre desenhos distantes e próximos da linha da dobra, os estudantes fizeram pequenos figuras em diferentes pontos do papel, para observar onde eles ficariam na parte interna. Um dos meninos afirmou que a dobra era é o meio papel, por isso que os desenhos próximos a ela ficavam no centro da folha na parte interna.

Figura 12

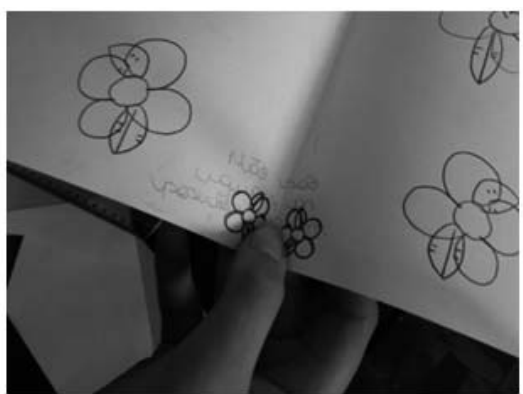

Fonte: elaboração dos autores.

A partir dessas deduções foi possível construir o conceito de eixo de simetria com os estudantes.

\section{$2^{a}$ etapa - investigando os eixos de simetria}

A proposta dessa etapa está no fato dos alunos perceberem que uma figura simétrica pode ter um ou mais eixos de simetria.

Os alunos deverão dividir a folha branca em duas partes ficando com duas folhas menores. A primeira será trabalhada da forma que está: um retângulo. A segunda deverá ser cortada, formando um triângulo.

Realizando dobraduras, os alunos deverão descobrir quantas e de quais maneiras podemos dividir a folha retangular em duas partes iguais. Serão encontrados 4 formas distintas, conforme a figura 13.

Figura 13

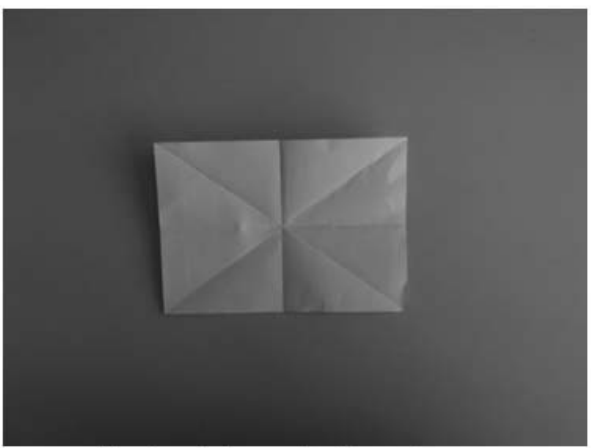

Fonte: elaboração dos autores. 

figura 14

No caso do triângulo, há apenas um eixo de simetria, conforme a

Figura 14

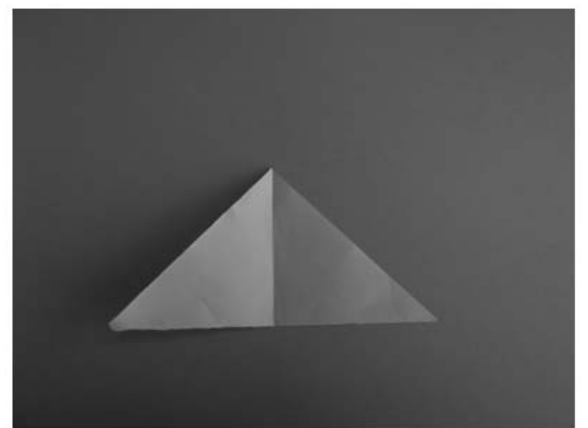

Fonte: elaboração dos autores.

$2^{a}$ etapa - investigando os eixos de simetria: análise da aplicação

Durante a execução dessa etapa, os estudantes tiveram facilidade em realizar as dobraduras e perceberam que, nem sempre, um eixo fará partes iguais se sobreporem, como no caso das diagonais de um retângulo. Entretanto, no momento da contagem dos eixos, os estudantes tiveram dificuldades e acabavam contanto o mesmo eixo duas vezes (na parte de cima e de baixo da figura). Para superar essa dificuldade não planejada, foi solicitado que os alunos desenhassem uma reta por cima de cada eixo, o que facilitou a contagem e superou o problema.

\section{Figura 15}

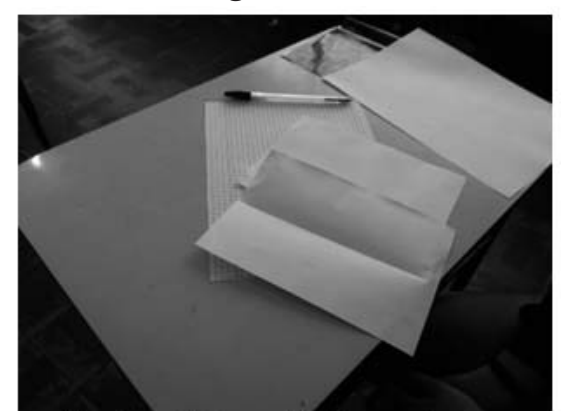

Fonte: elaboração dos autores.

\section{$3^{a}$ etapa - criando figuras simétricas e assimétricas a partir de comandos numéricos}

A proposta dessa etapa é que, a partir de sequências numéricas com comandos pré-estabelecidos, os alunos criem figuras simétricas e assimétricas. Também faz parte dessa etapa investigar quais os tipos de sequências geram figuras simétricas e assimétricas. 
Analisando figuras criadas a partir dessas sequências, os alunos deverão classifica-las em simétricas ou assimétricas. Nas figuras simétricas deverão identificar o(s) eixo(s) de simetria.

As figuras serão criadas em papel quadriculado a partir de comandos numéricos, girando sempre $90^{\circ}$. Quando o número for positivo, o giro será no sentido horário. Se o número for negativo, o giro será no sentido anti-horário. Os números representam a quantidade de quadrinhos que se deve andar em cada direção. O primeiro movimento é sempre do ponto de origem para cima. São exemplos de comandos as sequências:

a) 3, 9, 3, $9 \rightarrow$ Gera um retângulo, figura simétrica com 4 eixos de simetria (figura 16).

\section{Figura 16}

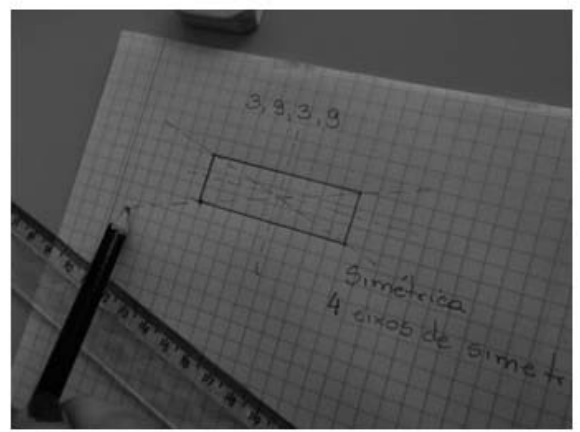

Fonte: elaboração dos autores.

b) 4, 9, 6, 8, 5, 7, 4, 6, 3, 3, $9 \rightarrow$ Gera uma figura assimétrica, conforme a figura 17 .

\section{Figura 17}

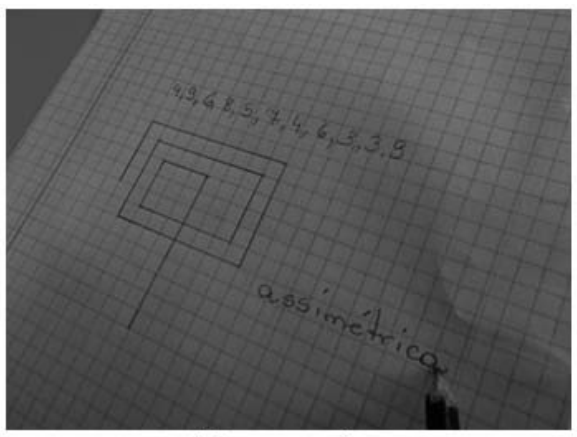

Fonte: elaboração dos autores.

c) $1,1,-1,1,-1,1,-1,1,-1,1,1,-1,1,-1,1,-1,1,-1,1, \rightarrow$ Gera uma figura simétrica com 1 eixo de simetria, conforme a figura 18. 


\section{Figura 18}

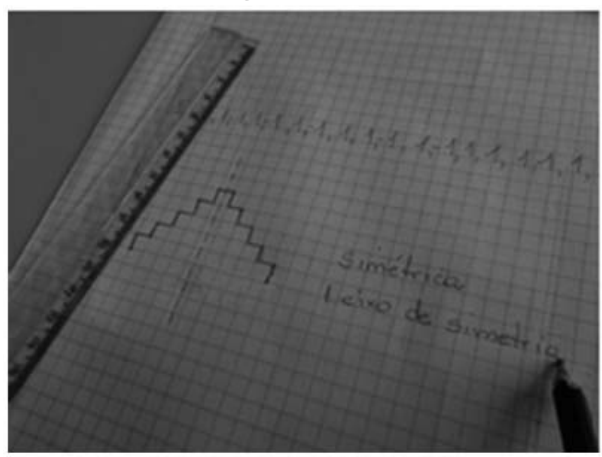

Fonte: elaboração dos autores.

Esses exemplos são apenas ideias de sequências numéricas para a criação das figuras. Outras poderão ser criadas para a aplicação da atividade.

O professor pode estimular o raciocínio dos alunos através de questões como: "o que podemos observar ao compararmos sequências de figuras simétricas e figuras assimétricas?"; "há simetria também nas sequências numéricas de figuras simétricas?”.

Investigando as sequências numéricas e as figuras criadas, os alunos perceberão que as sequências simétricas geram figuras que preservam essa característica, bem como aquelas sem nenhum padrão geram figuras assimétricas.

Outro ponto a ser explorado pelo professor é a criação de figuras simétricas por translação e rotação. Para criar figuras por translação basta repetir a sequência de comandos partindo de outro ponto no papel. As figuras simétricas por rotação exigem alterações na sequência numérica geradora. Para rotacionar uma figura em $180^{\circ}$, é necessário inverter os sinais dos números da sequência, ou seja, realizar cada movimento no sentido oposto do original. Para que ocorram rotações em outros ângulos, há a exigência da criação de uma nova sequência. Esse é o ponto de partida para uma nova investigação.

\section{$3^{a}$ etapa - criando figuras simétricas e assimétricas a partir de comandos numéricos: análise da aplicação}

A terceira etapa foi repensada dias antes da aplicação. Refletindo sobre essa parte da atividade, decidiu-se que seriam usados apenas comandos positivos (girar no sentido horário). Dependendo do desempenho e aceitação dos estudantes a esses comandos, seriam apresentadas as figuras construídas a partir de números positivos e negativos.

Entretanto, no momento que a terceira etapa da sequência didática iniciou, percebeu-se que essas foram as atividades mais motivadoras da proposta. Os estudantes receberam muito bem a atividade, 
sentiram-se desafiados a resolver cada um dos comandos e encontrar a figura. A terceira sequência numérica apresentada envolveu comandos positivos e negativos.

Figura 19

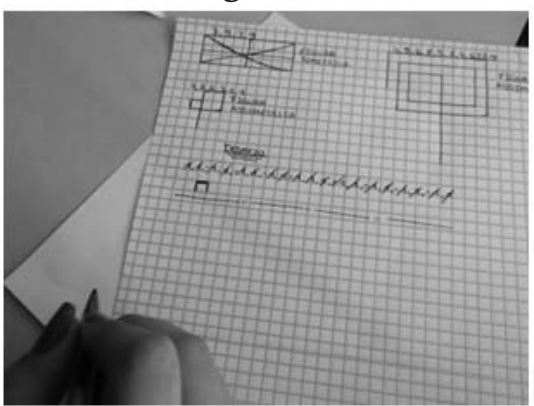

Fonte: elaboração dos autores.

Figura 20

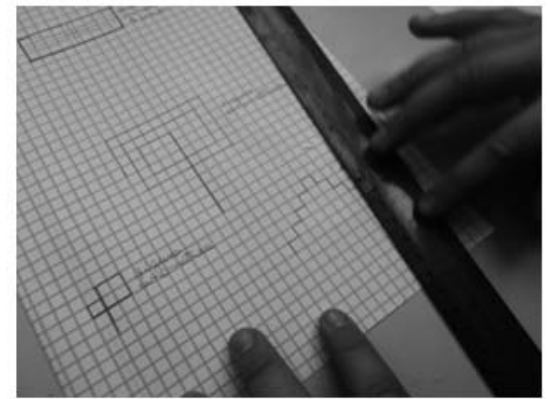

Fonte: elaboração dos autores.

Essa etapa da sequência didática foi trabalhada com mais empenho e concentração por parte dos estudantes do que as anteriores.

\section{$4^{a}$ etapa - criando sequências e figuras simétricas}

Nessa etapa os alunos trabalharão em duplas ou quartetos na seguinte dinâmica: cada aluno ou dupla construirá sua figura simétrica e anotará a sequência correspondente. Em seguida, as duplas ou quartetos trocarão as sequências entre si, sem mostrar a figura que será criada a partir daqueles comandos.

Ao receber a sequência, cada dupla ou aluno deverá desenhá-la e, a partir dela, criar figuras simétricas por translação, reflexão e rotação.

Apresenta-se, assim, uma proposta de atividade para a introdução do conteúdo de simetria em sala de aula baseada na investigação. Acredita-se que por esse motivo, tal proposta pode configurar em uma alternativa positiva para abordagem desse conteúdo, cuja relevância já foi salientada nesse trabalho.

568 Educação \& Realidade, Porto Alegre, v. 40, n. 2, p. 549-572, abr./jun. 2015. 
Alguns dos pontos positivos dessa atividade são os baixos custos dos materiais e a simplicidade de sua execução, dando ao professor a liberdade de realizá-la em sala de aula ou em outro espaço disponibilizado pela escola, como o pátio ou a biblioteca.

\section{$4^{a}$ etapa - criando sequências e figuras simétricas: análise da aplicação}

A quarta etapa da sequência didática foi encarada como uma competição. Cada um dos alunos queria construir a figura mais interessante e a sequência mais elaborada para trocar com o colega.

Figura 21

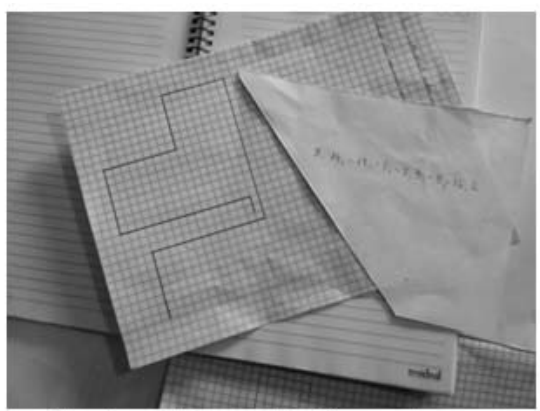

Fonte: elaboração dos autores.

A questão do desafio gerou motivação e empenho dos alunos. Entretanto, um ponto complicado foi a regra de não poder levantar o lápis do papel para desenhar. Isso gerou algumas dúvidas nos alunos, solucionadas com o auxílio dos professores.

\section{Algumas Considerações}

Tomando a didática da matemática como o conjunto de conceitos e teorias voltadas para especificidade do ensinar matemática, entende-se o quanto o planejamento do docente, bem como as concepções que ele carrega da sua disciplina, influenciam a tríade professor-aluno-saber. Além disso, é inegável a necessidade de algumas transformações no objeto matemático com a finalidade de adaptá-lo para a escola. Um caminho que pode ser escolhido pelo professor em seu planejamento, e na definição de tais adequações, é a (re)construção do contexto do objeto matemático a ser ensinado.

A intenção dessa (re)construção em sala de aula está longe de promover que os estudantes revivam situações de épocas passadas ou culturas estranhas a eles. O objetivo é tentar relacionar o conteúdo ensinado a situações que sejam mais compreensíveis aos alunos, ampliando suas ideias sobre o que estão aprendendo. Nesse processo a Etnomate- 
mática e a História da Matemática representam recursos valiosos para o professor.

A partir de um olhar histórico é possível perceber que a ideia de simetria, conteúdo abordado nessa proposta, antecede a linguagem matemática formal. A percepção de padrões simétricos em traços arquitetônicos e nas artes é reflexo da produção cultural de uma sociedade. Aliado a isso, salienta-se as matemáticas locais, ou Etnomatemáticas, que possibilitaram criações envolvendo padrões de simetria, que vão desde cestos e tapetes até grandes e imponentes edificações.

Até meados do século $\mathrm{XV}$, primava-se pela perfeição simétrica na construção de grandes templos visando agradar aos deuses. A partir do Renascimento, quando o homem voltou-se para si próprio, a simetria continuou garantindo em suas obras o padrão de beleza almejado na época.

Admitindo a necessidade e relevância do estudo das transformações geométricas na Educação Básica, em virtude do reconhecimento dessa característica geométrica na arquitetura, nas artes e até as formas da natureza, julga-se válida a iniciativa de procurar formas diferenciadas para o ensino dessa propriedade matemática na escola. Nessa linha de raciocínio, a investigação proporciona ao aluno um envolvimento com o conhecimento matemático em questão muito além do contato superficial com a teoria. Atividades como a apresentada nesse trabalho, possível inclusive em classes numerosas, são alternativas de baixo custo financeiro sem, no entanto, decréscimo de qualidade e viabilidade pedagógica.

Analisando-se a aplicação da sequência didática elaborada e descrita nesse artigo foi possível perceber o ganho pedagógico do trabalho envolvendo a investigação. Ao tentar encontrar uma maneira de solucionar os problemas, no caso os exercícios propostos, os estudantes sentiram-se desafiados, e isso os motivou durante a atividade. Tal condição, de desafio e uso da criatividade, vem ao encontro do conceito de engenharia didática que compara, guardadas as singularidades, o trabalho da sala de aula com o de um engenheiro.

Por outro lado, mesmo aparentando relativa simplicidade, a proposta de atividade experimentada conservou e deu ênfase aos conceitos matemáticos, no caso, relacionados à simetria, de forma ajustada às especificidades do meio escolar como preconiza, segundo Pais (2011), a didática da matemática. O planejamento e (re)construção do contexto, ancorados nas teorias apontadas nesse trabalho, foram determinantes para o sucesso na execução da proposta.

Acredita-se, a partir da elaboração, aplicação e análise dessa sequência didática, que outras possibilidades de trabalho podem surgir no campo da didática da matemática, considerando as especificidades de cada turma e/ou assunto tratado. 


\section{Notas}

1 As fases da Engenharia Didática como metodologia de pesquisa são: (1) análises preliminares; (2) concepção e análise $a$ priori; (3) aplicação de uma sequência didática e; (4) análise a posteriori e avaliação (Pais, 2011).

2 Vitrúvio fez um dos mais conhecidos estudos sobre simetria dos templos e apresenta a proporção entre as partes do corpo tal qual a cabeça seria 1/8 da altura do corpo, os pés seriam 1/6 do corpo e a face 1/10 do corpo. Essa regra indica espantosa diferença com a natural harmonia corporal, como fazem alguns comentários da renascença, que muitos estimulam a correção. Assim, Leonardo da Vinci, informa para a largura do busto como 1/4 da altura do corpo, cuja razão aplica-se sobre os ombros. Da Vinci também reduziu o pescoço de $1 / 15$ do corpo humano para $1 / 24$ e o pé de $1 / 6$ da altura do corpo para $1 / 7$ (Santos, 2007, p. 4).

\section{Referências}

ARTEESPAÑA. Arte Sumerio. 2005. Disponível em: <http://www.arteespana. com/artesumerio.htm>. Acesso em: 09 fev. 2015.

BOYER, Carl Boyer; MERZBACH, Uta C. História da Matemática. Tradução de Helena Castro. 3. ed. São Paulo: Blücher, 2012.

BRASIL. Parâmetros Curriculares Nacionais: matemática. Brasília: MEC/SEF, 1998.

BROUSSEAU, Guy. Didática e Teoria das Situações Didáticas em Matemática. Tradução de Maria José Ferreira da Silva e Saddo Ag Almouloud. São Paulo: PUC, 2006. Disponível em: <http://www.pucsp.br/pensamentomatematico/TSDMF4_Brousseau_2006.pdf $>$. Acesso em: 20 dez. 2013.

CAFÉ HISTÓRIA. Coliseu de Roma. 2008. Disponível em: <http://cafehistoria. ning.com/photo/1980410:Photo:45178?context=popular>. Acesso em: 22 jan. 2013.

D’AMBRÓSIO, Ubiratan. Educação Matemática: da teoria à prática. 23. ed. Campinas: Papirus, 2012. (Coleção Perspectivas em Educação Matemática).

D’AMBROSIO, Ubiratan. Etnomatemática: elo entre as tradições e a modernidade. 2. ed. Belo Horizonte: Autêntica, 2007.

D’AMORE, Bruno. Epistemologia, Didática da Matemática e Práticas de Ensino. Bolema - Boletim de Educação Matemática, Rio Claro, v. 20, n. 28, p. 1179-1205, 2007.

ECO, Umberto. Arte e Beleza na Estética Medieval. Lisboa: Presença, 1989.

ENRIGHT, Carolyn. Técnicas de Arte no Egito Antigo. 2013. Disponível em: <http://www.ehow.com.br/tecnicas-egito-antigo-info_6935/> Acesso em: 09 jan. 2013.

GUIA Geográfico. Grécia - Atenas. Partenon na Acrópole de Atenas. 2008. Disponível em: <http://www.guiageo-grecia.com/partenon.htm>. Acesso em: 03 fev. 2013.

PAIS, Luiz Carlos. Didática da Matemática: uma análise da influência francesa. 3. ed. Belo Horizonte: Autêntica, 2011. (Coleção Tendências em Educação Matemática). 
PIMENTA, Selma Garrido. Para uma Re-significação da Didática: ciências da educação, pedagogia e didática (uma revisão conceitual e uma síntese provisória). 2013. Disponível em: <http://www.geocities.ws/byrooney/arquivos/arquivos/resigdid.doc>. Acesso em: 28 dez. 2013.

PONTE, João Pedro et al. Investigações Matemáticas na Sala de Aula. Belo Horizonte: Autêntica, 2003.

ROONEY, Anne. A História da Matemática: desde a criação das pirâmides até a exploração do infinito. São Paulo: M. Books do Brasil, 2012.

SANTOS, Maria Madalena dos. A Matemática da Arquitetura Ideal. Curitiba: Graphica, 2007. Disponível em: <http://www.exatas.ufpr.br/portal/docs_degraf/artigos_graphica/A\%20MATEMATICA\%20DA\%20ARQUITETURA\%20 IDEAL.pdf>. Acesso em: 15 jan. 2013.

SILVA, Tiago Ferreira da. Infoescola. Período Neolítico. 2008. Disponível em: $<$ http://www.infoescola.com/pre-historia/periodo-neolitico/>. Acesso em: 20 jan. 2013.

SILVA, Veleida Anahi da. Relação com o Saber na Aprendizagem de Matemática: uma contribuição para a reflexão didática sobre as práticas educativas. Revista Brasileira de Educação, Rio de Janeiro, v. 13, n. 37, p. 150-190, jan./abr. 2008.

UM OLHAR sobre a Arte. A Arte da Antiguidade - Arte Egípcia. 2008. Disponível em: $<$ http://umolharsobreaarte.blogs.sapo.pt/tag/pintura+eg\%C3\%ADpcia >. Acesso em: 19 jan. 2013.

Lidiane Schimitz Lopes é mestra em Ensino de Ciências e Matemática pelo PPGECM da UFPel (2013). Especialista em Estudos Matemáticos - Ênfase em Educação Matemática pela UFPel (2012). Licenciada em Matemática pela Universidade Federal do Pampa (2010). Pesquisadora nas áreas de História da Matemática e Formação Inicial de Professores.

E-mail: lidischimitz@hotmail.com

Gilson Leandro Pacheco Alves é mestre em Ensino de Ciências e Matemática pelo PPGECM da UFPel (2014). Especialista em Estudos Matemáticos - Ênfase em Educação Matemática pela UFPel (2012). Licenciado em Matemática pela Universidade Federal do Pampa (2010). Pesquisador na área de etnomatemática.

E-mail: gilsonlalves@hotmail.com

André Luís Andrejew Ferreira é doutor em Informática na Educação pelo PPGIE/UFRGS. Atualmente está lotado no Departamento de Matemática e Estatística da UFPel, coordenador do subprojeto Matemática/Noturno da CAPES/PIBID/5a CRE-UFPel, atuando também na área de Ensino de Matemática e professor do Programa de Pós-Graduação em Ensino de Ciências e Matemática da Faculdade de Educação/UFPel.

E-mail: andrejew.ferreira@gmail.com 